\title{
Competências da docência para o Ensino e a Pesquisa na perspectiva da sustentabilidade profissional
}

\author{
Teaching competencies for Teaching and Research from the perspective of professional \\ sustainability \\ Competencias didácticas para la Docencia y la Investigación desde la perspectiva de la \\ sostenibilidad professional
}

Recebido: 15/01/2021 | Revisado: 17/01/2021 | Aceito: 20/01/2021 | Publicado: 25/01/2021

\author{
Carla Maria Holanda de Lima Façanha \\ ORCID: https://orcid.org/ 0000-0003-1443-9893 \\ Faculdade Gestão de Negócios, Brasil \\ E-mail: carlamariaholanda@gmail.com \\ Fabiana Pinto de Almeida Bizarria \\ ORCID: https://orcid.org/ 0000-0001-8365-8593 \\ Faculdade Luciano Feijão, Brasil \\ E-mail: trabalhoegestao.flf@gmail.com/bianapsq@hotmail.com
}

Universidade da Integração Internacional da Lusofonia Afro-Brasileira, Brasil

\begin{abstract}
Resumo
Demandas da sociedade impõem desafios ao docente do Ensino Superior, diante da internacionalização, diversidade cultural, novas concepções educativas e da demanda por produção acadêmica. Frente à essa realidade, surge a ideia de que as competências docentes precisam ser sustentáveis, ou seja, flexíveis, adaptáveis e estratégicas. Com esse argumento, questiona-se sobre quais dimensões definem competências do docente do Ensino Superior no contexto da sua sustentabilidade profissional. Para tanto, objetiva-se dimensionar competências do docente para o ensino e a pesquisa e compreendê-las à luz das demandas profissionais da atualidade. A pesquisa apresenta etapa quantitativa, na qual efetuou Análise Fatorial Exploratória e Análise Fatorial Confirmatória, com base nas respostas (213 docentes) ao questionário (adaptado) do instrumento de Pereira (2007); e qualitativa, com base em três entrevistas semiestruturas (Gestores da área de Ensino, Pesquisa e Extensão), identificando dimensões na fase quantitativa aos conteúdos, quando, por meio de co-ocorrências, discutiu-se sobre competências sustentáveis do docente. A sustentabilidade associa-se ao agrupamento das seis dimensões, que foram: flexibilidade, que se desdobra em empatia, proatividade e adaptação; à habilidade com gestão, no sentido do saber-fazer diante das atividades cotidianas; ao potencial didáticopedagógico, que alia conhecimentos em sintonia com um ambiente interativo e comunicativo; ao compromisso ético, diante da responsabilidade social e política; à Inovação e à Cooperação, em busca de formulações inovativas. Palavras-chave: Competências sustentáveis; Competências do docente; Mercado de trabalho.
\end{abstract}

\begin{abstract}
Demands of society impose challenges to the Higher Education teacher, facing the internationalization, cultural diversity, new educational conceptions and the demand for academic production. Faced with this reality, the idea arises that the teaching competences need to be sustainable, that is, flexible, adaptable and strategic. With this argument, it is questioned what dimensions define the competences of the Higher Education teacher in the context of their professional sustainability. In order to do so, the objective is to dimension teacher competences for teaching and research and to understand them in the light of current professional demands. The research presents a quantitative step, in which it carried out Exploratory Factor Analysis and Confirmatory Factor Analysis, based on the answers (213 teachers) to the (adapted) questionnaire of the Pereira instrument (2007); and qualitative, based on three semistructured interviews (managers of the area of Teaching, Research and Extension), identifying dimensions in the quantitative phase to the contents, when, through co-occurrences, it was discussed about sustainable teacher competences. Sustainability is associated with the grouping of the six dimensions, which were: flexibility, which unfolds in empathy, proactivity and adaptation; to the ability with management, in the sense of know-how in front of the daily activities; to the didactic-pedagogical potential, which combines knowledge in harmony with an interactive and communicative environment; to ethical commitment, to social and political responsibility; to Innovation and Cooperation, in search of innovative formulations.
\end{abstract}

Keywords: Sustainable skills; Teacher competences; Job market. 


\begin{abstract}
Resumen
Las demandas de la sociedad imponen desafíos al docente de la Enseñanza Superior, ante la internacionalización, diversidad cultural, nuevas concepciones educativas y la demanda por producción académica. Frente a esta realidad, surge la idea de que las competencias docentes necesitan ser sostenibles, es decir, flexibles, adaptables y estratégicas. Con ese argumento, se cuestiona sobre qué dimensiones definen competencias del docente de la Enseñanza Superior en el contexto de su sustentabilidad profesional. Para ello, se objetiva dimensionar competencias del docente para la enseñanza y la investigación y comprenderlas a la luz de las demandas profesionales de la actualidad. La investigación presenta etapa cuantitativa, en la cual efectuó Análisis Factorial Exploratorio y Análisis Factorial Confirmatorio, con base en las respuestas (213 docentes) al cuestionario (adaptado) del instrumento de Pereira (2007); y cualitativa, con base en tres entrevistas semiestructuras (Gestores del área de Enseñanza, Investigación y Extensión), identificando dimensiones en la fase cuantitativa a los contenidos, cuando, por medio de corresponsales, se discutió sobre competencias sostenibles del docente. La sustentabilidad se asocia a la agrupación de las seis dimensiones, que fueron: flexibilidad, que se desdobla en empatía, proactividad y adaptación; a la habilidad con gestión, en el sentido de los conocimientos técnicos frente a las actividades cotidianas; al potencial didáctico-pedagógico, que combina conocimientos en sintonía con un ambiente interactivo y comunicativo; al compromiso ético, ante la responsabilidad social y política; a la Innovación ya la Cooperación, en busca de formulaciones innovadoras.
\end{abstract}

Palabras clave: Competencias sostenibles; Competencias del docente; Mercado de trabajo.

\title{
1. Introdução
}

O trabalho do professor universitário tem sido alvo de importantes debates nas últimas décadas (Nassif, Hanashiro \& Torees, 2010, Valente \& Viana, 2011). Pesquisas sobre qualidade do Ensino Superior indicam que o desempenho docente é reflexo de processos formativos, envolvendo o desenvolvimento de competências para atender demandas do mercado, que se revela cada vez mais seletivo (Medeiros, 2007, Ferreira, 2015).

O cenário competitivo das organizações impõe às Instituições de Ensino Superior (IEs), a necessidade de um posicionamento estratégico e, com isso, adaptações na estrutura organizacional, pessoal, métodos, técnicas e materiais (Knowles, 1980). Nessa lógica, fala-se que esses profissionais precisam adaptar-se às mudanças contextuais de um mundo globalizado (Michaux, 2011, Severino, 2013).

Variedade de formas de ensino, por exemplo, exige que o docente exerça um papel multidimensional, quando ensino, pesquisa e extensão agregam-se à formação internacionalizada, com ampliação de parcerias educacionais e consideração à diversidade cultural (Nassif \& Hanashiro 2005, Teichler, 2004, Guitel, 2006, Beshara, 2016, Brackmann, 2013, Souza, 2010). Além disso, avanços nas Tecnologias Digitais de Informações e Comunicações (TDIC) acrescentam desafios inerentes à nov as concepções educativas (Nivala, 2009), e a demanda por produção acadêmica com foco em rankings nacionais e internacionais impõe status competitivo ao seu exercício (Sguissardi \& Silva Jr., 2009), o que reflete em competências diferenciadas.

Surge, então, a ideia de que competências docentes precisam ser sustentáveis, ou seja, flexíveis, adaptáveis e estratégicas, compatíveis com as demandas de um mercado de trabalho em contínua mudança (Almeida, 2008, Veiga, 2011). Competências estas requisitadas na reformulação de projetos político-pedagógicos, situando preocupações dos próprios docentes em relação à carreira, bem como em atenção à exigências normativas (Campos, Silva \& Cicillini, 2015). Com isso, novos conhecimentos, novas habilidades e atitudes podem repercutir em uma maior sustentabilidade profissional.

No Brasil, de acordo com Valente e Viana (2011), essas questões sobre as mudanças de paradigmas na educação têm trazido mudanças nos projetos político-pedagógicos das instituições de ensino, de um lado, por exigência legal e, de outro, legitimados pela preocupação dos próprios docentes, com a formação de profissionais críticos e reflexivos, para um mercado competitivo. Diante disso, uma outra preocupação se volta para a prática docente, a partir do desenvolvimento de competências sustentáveis para atender as demandas da contemporaneidade.

Em análise, competências sustentáveis alinham-se à demandas do mercado de trabalho, embora este também seja pensando no desenho dos cursos, o que é suscitado quando a leitura de mercado é promovida por profissionais críticos e flexíveis (Valente \& Viana 2011). Tanto no âmbito da docência, como na formação que esta propicia, esses aspectos se tornam elementares à defesa da ideia de "sustentabilidade". 
Pesquisas que abordam a docência como profissão ainda dão ênfase ao processo de ensino-aprendizagem, como o estudo de Nassif e Hanashiro (2005), ou, ainda, em interação com a atuação em pesquisa, como o de Pereira (2007). A extensão tem emergido nesse campo de estudo, particularmente por meio de experiências de projetos extensionistas, a exemplo do que se apresenta nas coletâneas de Addor e Lianza (2015), Addor e Henriques (2015) e Addor (2015), fruto de atividades do Núcleo de Solidariedade Técnica (Soltec), vinculado ao Departamento de Engenharia Industrial da Escola Politécnica da Universidade Federal do Rio de Janeiro. Tais experiências, contudo, se apresentam em processo de elaboração-reflexão, sem delimitação de suas atividades por meio de competências docentes específicas.

As pesquisas de Almeida (2008), Lima (2003) e Moura e Soares (2009), tratam da relação entre sustentabilidade e profissão, porém, sem avançar a discussão para o docente. Assim, considera-se necessário inserir essa discussão, quando a formação desse profissional envolve não apenas a situação em que ele terá que formar profissionais para o mercado de trabalho, mas ele próprio a se considerar inserido nesse contexto.

Com esse argumento, questiona-se sobre quais dimensões definem competências do docente do Ensino Superior no contexto da sua sustentabilidade profissional? Para tanto, objetiva-se dimensionar competências do docente para o ensino e a pesquisa e compreendê-las à luz de demandas profissionais da atualidade.

Nesse sentido, parte-se do estudo de Pereira (2007) que aborda competências do docente relacionadas ao ensino e à pesquisa. O instrumento do autor é adaptado e aplicado à fim de verificar as dimensões emergentes (associando ensino e pesquisa), com base em Análise Fatorial Exploratória (AFE) e Análise Fatorial Confirmatória (AFC). Com esse estudo, partese para a compreensão dessas dimensões com suporte em entrevistas semiestruturadas, junto à docentes gestores de uma Instituição de Ensino Superior. As dimensões identificadas, então, são associadas às entrevistas no âmbito de uma discussão sobre competências sustentáveis do profissional docente.

\section{Competências do Profissional Docente no Ensino Superior}

As organizações se encontram em constante competitividade e, por isso, atentas à novos aprendizados e novas estratégias para maximizar as possibilidades de sobrevivência (Fleury \& Fleury, 2001, 2004). Nesse contexto, a competência se torna condição necessária para lidar com o contexto globalizado, complexo e competitivo (Nassif \& Hanashiro, 2005), sendo ela definida em duas abordagens: as Competências Individuais (McClelland, 1973) e as Competências da organização (Hamel \& Prahalad, 1995, Ruas; 2005).

Competências individuais são vistas como essenciais, situam a adaptabilidade do homem em diferentes contextos e, por serem particulares, são menos passíveis de disseminação (Prahalad \& Hamel, 1990). No âmbito dessas, têm-se o saber agir, que implica mobilizar, integrar, se responsabilizar, características pessoais que agregam valor à organização à sociedade e ao indivíduo (Fleury \& Fleury, 2001, 2004, Zarifian, 2001). Competências organizacionais, por sua vez, envolvem o saber-fazer coletivo, uma articulação de recursos organizacionais (pessoas, tecnologia, estrutura de gestão) (Prahalad \& Hamel, 1990).

Na leitura de Bonfim (2012), inicialmente, acreditava-se que sobre as competências individuais se desenvolviam na interação do homem com a sociedade, e as organizacionais seriam aquelas necessárias para o exercício da função. Com o avanço dos estudos, as competências passaram a ser analisadas em conjunto, quando as individuais são mais contextualizadas às organizações, posto que os conhecimentos adquiridos só apresentam status de competência se ocorrer compartilhamento, em rede, em processo de comunicação (Fleury \& Fleury, 2001, 2004, Dutra, 2004); e as organizacionais passam a considerar os conhecimentos particulares dos membros, dinamizados na integração e transferência de competências individuais referidas ao contexto profissional (Le Boteerf, 2003).

Nessa lógica, competência individuais e organizacionais fazem parte de um continuo, quando a transformação de uma e de outra depende da dinâmica entre indivíduos e organizações (Perrenound, 2000). De forma genérica, então, associa-se a 
ideia de competência à capacidade de apreciar e resolver problemas dentro de um contexto (Boog, 1991).

No âmbito educacional, as competências envolvem não apenas um saber-fazer, mais avança para um saber-fazertransmitir, referenciado em estratégias pedagógicas resolutivas (Le Boterf, 2003). Além do ato de ensinar, outras atividades cercam esse profissional, seja no âmbito da pesquisa, da extensão, seja no âmbito da gestão (Perrenound, 2000; Pereira, 2007, Brasil, 2009).

As competências docentes acabam por centrar esforços no "ensinar", sendo outras atividades situadas numa discussão complementar, como observa-se em Masetto (2003) e Perrenound (2000) e Freire (1997). Especificamente a competência pedagógica é definida por Masetto (2003) em três dimensões: domínio de uma área de conhecimento (saber teórico-prático adquirido na formação e exercício profissional); domínio pedagógico (essencial, mas visto como fragilizado pelo fato do pouco investimento na área); e o exercício da dimensão política (como cidadão, o compromisso com a sociedade).

Apesar de Perrenound (2000) pesquisar a docência nos ensinos médio e fundamental, compreende-se implicação das competências que define para a formação superior, no caso: planejar e aplicar experiências de aprendizagem; administrar o desenvolvimento das aprendizagens; criar e fazer surgir os dispositivos de diferenciação; envolver os alunos na construção da aprendizagem; trabalhar em conjunto com outros docentes e alunos; participar da administração da escolar; utilizar novas tecnologias; enfrentar as questões éticas da profissão; e buscar seu próprio aperfeiçoamento profissional. Freire (1997), por sua vez, fala que o exercício da docência precisa de método, pesquisa ética e criatividade, com postura de humildade, bom senso, alegria e esperança.

As competências do docente universitário na concepção de Nassif e Hanashimiro (2005) envolvem a dimensões técnica, com a competência didática e teórica; a interpessoal, com a comunicacional e motivacional; a intelectual, com a busca de novos conhecimentos; social, com a ética e o comportamento equilibrado; a dimensão metódica e participativa, com as respectivas competências relacionadas à preparação de aula e feedback dos trabalhos realizados; e flexibilidade, iniciativa e ação.

Outras competências são introduzidas ao rol, como, por exemplo, as que envolvem conhecimento (Ubeda, 2003), criatividade (Dudziak, 2003, Ubeda; 2003), ética, visão sistêmica, liderança trabalho em equipe (Ubeda, 2003), empatia (Leite Filho, Martins, 2006), flexibilidade (Dudziak, 2003, Ubeda, 2003) e proatividade (Dudziak, 2003).

No que se refere à pesquisa, as normativas indicam a indissociabilidade entre ensino, pesquisa e extensão, na leitura de Pereira (2007) essas relações podem, de fato, ser integradas, o que é mais perceptível ao nível da pós-graduação, mas, também, dissociadas, quando o docente se envolve exclusivamente com o ato de ensinar. O relacionamento entre ensino e pesquisa consiste mais em um desejo da academia do que, de fato, uma realidade (Campos, Silva \& Cicillini, 2015). Considerando as tensões nas demandas que esse relacionamento impõe, tanto o docente, como a cultura organizacional, ou mesmo interesses políticos interferem nesse contexto (Healey, 2005).

Como exemplo, têm-se a Conferência Mundial de Educação Superior, ocorrida em 1998, que introduz quatro recomendações às IEs: variedade de serviços à sociedade; a multidimensionalidade da docência, com o foco em pesquisa e extensão; a internacionalização; e o avanços das TDIC (Nassif \& Hanashiro, 2005, Nivala, 2009). A essas recomendações somam-se intensos movimentos de reforma em debate nas décadas de 1980 e 1990 que impactam na demanda pela ampliação do acesso à Educação Superior para as classes menos favorecidas (Arocena \& Sutz, 2005).

Tanto a democratização do acesso percebida nas décadas seguintes, como a abertura à novas culturas por meio da experiência com a internacionalização, exigem novas capacidades comunicacionais por parte do docente que, agora, além de “ensinar" deve, cada vez mais, preocupar-se com o "como ensinar" diante da diversidade cultural (Beshara, 2016, Brackmann, 2013, Souza, 2010). Com a Educação a Distância, os desafios se intensificam, haja vista a interação discente-docente mediada pela tecnologia, sendo esta, muitas vezes, apreendida durante o processo, ou seja, sem que se tenha formação prévia (Nivala, 
2009, Joly \& Silva, Almeida 2012).

Diante desse contexto, têm-se que a formação tradicional de professores, como um processo de transmissão de conhecimentos científicos e culturais, centrada no domínio de conceitos e estrutura de assuntos, em que é especialista, não mais se mostra satisfatória para o exercício da função (Marli, 2010). Além dos aspectos pedagógicos, outros elementos são somados à ideia de competência docente, por meio de novas concepções de desempenho, efetividade, utilização de novos recursos, capacidade de realizar determinada atividade em função de um contexto organizacional, inclusão da relação trabalhador/e trabalho com enfoque mais social (Moura \& Soares, 2009).

Na leitura de Moura e Soares (2009) e Duarte (2004), por exemplo, essas competências passam a ser sustentáveis se mais flexíveis, estratégicas, adaptáveis e compatíveis com demandas do mercado. Nessa concepção, ser sustentável é ser empregável, posto que a empregabilidade amplia as oportunidades em diferentes contextos socioeconômicos, por exemplo. Ser sustentável, ainda, envolve elo com a sociedade, assumindo postura crítico-política; meio ambiente, diante da consciência ecológica e atitude de proteção dos recursos naturais; com a economia, pela relação desta com a melhoria de condições sociais em respeito ao meio ambiente.

Ao docente no Ensino Superior, então, compete competências menos cristalizadas em conhecimentos adquiridos, mas conhecimentos, habilidades e atitudes voltadas à inovação e a cooperação, sendo elementar à ideia de conhecimento compartilhado (Almeida, 2008), e às construções coletivas de alternativas superadoras de problemas que emergem na atividade profissional (Rebelo, Pessoa \& Barreira, 2010). Aprender e criar coletivamente, em contextos de mudanças, tornam-se prerrogativas essenciais à ideia de competência docentes sustentáveis (Lima, 2003).

Traduzindo esses argumentos para o campo da gestão, têm-se que a ideia de que competências sustentáveis mobilizam recursos internos à organização (Instituição de Ensino) na geração de valor (Vasconcelos \& Cyrino, 2000), sendo este associado à inovação (valor econômico, valor social, valor ambiental). Com isso, têm-se que competências sustentáveis geram vantagem competitiva sustentável para a instituição (Phahalad \& Hamel, 1990; Barney; Hesterly, 2007). Quando se fala nesses termos no âmbito do Ensino Superior, pode-se supor, por exemplo vantagens competitivas no âmbito de obtenção de recursos para pesquisa, quando as IEs podem colocar-se como referência na produção de conhecimento favorável à melhoria das condições de vida

\section{Metodologia}

A pesquisa, registrada na Plataforma Brasil, foi aprovada pelo Comitê de Ética em Pesquisa da instituição de vínculo dos autores, sob o parecer n. 1706.456, em atenção à Resolução CNS/MS 466/12 e diretrizes. A pesquisa possui duas etapas: uma quantitativa e uma qualitativa.

Com o objeto de dimensionar competências docentes, na primeira etapa, realizou-se pesquisa quantitativa junto à 213, de uma população aproximada de 1200, docentes, vinculados à uma Instituição de Ensino Superior privada, com status de Universidade. A instituição é composta por quatro centros de ciências, que se dividem em: Centro de Ciências da Saúde (CCS), Centro das Ciências da Comunicação e Gestão (CCG), Centro de Ciências Jurídicas (CCJ) e Centro de Ciências Tecnológicas (CCT).

Para tanto, utilizou-se o instrumento de Pereira (2007), com uma escala likert de 10 pontos. O autor desenvolveu duas escalas, uma para o ensino e outra para a pesquisa, cada uma com 25 itens. Adaptação do instrumento resultou em questionário único, associando ensino e pesquisa, computando 30 itens, que foi enviado aos docentes por e-mail (formulário do Google Docs). Como os respondentes apenas enviavam o formulário com o preenchimento de todos os itens, não identificou-se missing values.

Considerando que Pereira (2007), ao dimensionar as competências, fez uso de teorias e não avançou em análises que 
confirmassem a disposição os itens em relação às dimensões criadas, foram realizadas duas Análises Fatoriais. A primeira, exploratória, com suporte no Statistical Package for the Social Sciences, (SPSS), versão 22, objetivou identificar um conjunto reduzido de variáveis latentes (fatores ou constructos) que explicasse a estrutura correlacional observada entre um conjunto de itens, tendo em vista os resultados dos testes Kaiser-Meyer-Okin (KMO) e o de esfericidade de Bartlett, Rotated Commponente Matrix. Nesse caso, atende-se à recomendação de Hair et al. (2009) de, no mínimo, cinco vezes mais observações do que o número de variáveis e amostras maiores que 100 observações.

Sendo a AFE indicada quando não há informação prévia sobre a estrutura fatorial que pode explicar as correlações entre os itens (Marôco, 2014), nessa pesquisa, mesmo que Pereira (2007) tenha sugerido o dimensionamento das competências, observou-se a possibilidade de algumas dimensões compartilharem de uma mesma estrutura correlacional e, por isso, optou-se iniciar pela AFE.

Com o resultado da AFE, realizou-se Análise Fatorial Confirmatória (AFC) para confirmar padrões estruturais, com base no método Partial Least Squares Path Modeling (PLS-PM), sendo este possível sem a suposição de normalidade multivariada (Hair Jr., Gabriel \& Patel, 2014), que, na leitura de Marôco (2014, p. 25) resulta da "ausência de pressupostos fortes sobre a forma de e sobre a multicolinearidade das variáveis nos modelos". Para a análise, utilizou-se o software SmartPLS (versão 3.0).

Na perspectiva de compreender as dimensões (fatores) relativas às competências docentes em função das demandas profissionais da atualidade, realizou-se, na segunda etapa, entrevista semiestruturada com três docentes gestores de três áreas de atuação: ensino, pesquisa e extensão. As entrevistas foram gravadas, totalizando 1 hora e 51 minutos de áudio transcrito. Com a Análise de Conteúdo identificou-se relações de co-ocorrências, ou seja, “(...) relações entre os elementos da mensagem, (...) presenças simultâneas (co-ocorrências ou relação de associação) “. (Bardin, 2011, p. 259-260). Nesse caso, busca-se as coocorrências em função das categorias operacionais da pesquisa (Minayo, 2014), no caso, as dimensões identificadas na etapa quantitativa.

\section{Resultados}

O perfil dos respondentes apresentou as seguintes características: gênero feminino (55\%); faixa etária entre 30 e 50 anos (62\%); titulação de mestrado (56\%) e doutorado (25\%); experiência acima de 8 anos com docência (67\%); regime de trabalho na categoria horista (49\%), exercendo apenas a função de docência (60\%), com atuação dos centros de CCG (19\%), CCS (43\%), CCT (22\%), CCJ (12\%); com ocupação nas áreas de ensino (35\%), ensino e pesquisa (38\%) e as áreas de ensino, pesquisa e extensão (17\%).

Dois testes estatísticos indicam a viabilidade da AFE. O teste Kaiser-Meyer-Olkin Measure of Sampling Adequacy (KMO), com valor de 0,926 , representa valor superior à 0,70 (valor de referência), o que indica que a amostra possui correlações entre pares de variáveis que podem ser explicadas por outras variáveis (Fatores). Com o teste de esfericidade de Barlett (BTS), por sua vez, sugere-se a existência de relação suficiente entre os indicadores para aplicação da AF (Bezerra, 2012). Nesse caso, a estatística qui-quadrado aproximada é de 4085,462, com 435 graus de liberdade, significativa ao nível de 0,000. Para que seja possível a AF, recomenda-se que o valor de Sig. (teste de significância) não ultrapasse 0,05 (Bezerra, 2012). Com esses testes têm-se que a AFE é adequada à amostra, sendo o passo seguinte a determinação do número de fatores que serão extraídos (Tabela 1). 
Research, Society and Development, v. 10, n. 1, e47810112007, 2021

(CC BY 4.0) | ISSN 2525-3409 | DOI: http://dx.doi.org/10.33448/rsd-v10i1.12007

Tabela 1 - Determinação do total de Fatores.

\begin{tabular}{|c|c|c|c|c|c|c|c|c|c|}
\hline \multicolumn{10}{|c|}{ Total Variance Explained } \\
\hline & \multicolumn{3}{|c|}{ Initial Eigenvalues } & \multicolumn{3}{|c|}{$\begin{array}{c}\text { Extraction Sums of Squared } \\
\text { Loadings }\end{array}$} & \multicolumn{3}{|c|}{$\begin{array}{c}\text { Rotation Sums of Squared } \\
\text { Loadings }\end{array}$} \\
\hline & Total & $\begin{array}{c}\% \text { of } \\
\text { Variance }\end{array}$ & $\begin{array}{c}\text { Cumulativ } \\
e \%\end{array}$ & Total & $\begin{array}{c}\% \text { of } \\
\text { Variance }\end{array}$ & $\begin{array}{c}\text { Cumulativ } \\
\text { e } \%\end{array}$ & Total & $\begin{array}{c}\% \text { of } \\
\text { Variance }\end{array}$ & $\begin{array}{c}\text { Cumulative } \\
\%\end{array}$ \\
\hline 1 & 12,707 & 42,358 & 42,358 & 12,707 & 42,358 & 42,358 & 4,206 & 14,019 & 14,019 \\
\hline 2 & 2,028 & 6,760 & 49,118 & 2,028 & 6,760 & 49,118 & 3,976 & 13,255 & 27,274 \\
\hline 3 & 1,689 & 5,629 & 54,747 & 1,689 & 5,629 & 54,747 & 3,527 & 11,756 & 39,030 \\
\hline 4 & 1,501 & 5,004 & 59,751 & 1,501 & 5,004 & 59,751 & 3,080 & 10,268 & 49,298 \\
\hline 5 & 1,188 & 3,962 & 63,713 & 1,188 & 3,962 & 63,713 & 2,655 & 8,850 & 58,148 \\
\hline 6 & 1,056 & 3,519 & 67,232 & 1,056 & 3,519 & 67,232 & 2,475 & 8,249 & 66,397 \\
\hline 7 & 1,027 & 3,424 & 70,655 & 1,027 & 3,424 & 70,655 & 1,277 & 4,258 & 70,655 \\
\hline 8 &, 819 & 2,729 & 73,385 & & & & & & \\
\hline
\end{tabular}

Nota 1: A tabela continua até a linha 30, sendo subtraída a partir da linha nove em função do espaço

Nota 2: Extração pelo componente principal, tipo de rotação ortogonal pelo método Varimax

Nota 3: Nível de significância utilizada é de $5 \%(0,05)$

Fonte: Dados da pesquisa.

Sob o critério da raiz latente, apenas fatores que têm raízes latentes (ou autovalores) acima de 1,0 são considerados significantes (Hair Jr. et al. 2009; Malhotra, 2012). Com isso, a Tabela 1 indica a existência de sete fatores a explicar as variáveis do instrumento, com 70,65\% da variância explicada, acima do percentual de 60\%, como sugere Hair Jr. et al. (2009).

Ainda em relação à AFE, a Tabela 2 apresenta a matriz rotacional, quando se estabeleceu o valor de 0,40 como carga fatorial significante para classificar a distribuição das variáveis entre os fatores, seguindo recomendação de Hair Jr. et al. (2009). Por meio da matriz, pode-se verificar a relação entre variáveis e fatores. Há que se notar que há variáveis com mais de uma carga fatorial relevante, no caso, as variáveis Q15, Q8, e Q13. 
Tabela 2 - Matriz rotacionada dos componentes dos fatores.

\begin{tabular}{|c|c|c|c|c|c|c|c|}
\hline & \multicolumn{7}{|c|}{ Component } \\
\hline & 1 & 2 & 3 & 4 & $s$ & $\sigma$ & 7 \\
\hline Q30 & .793 & & & & & & \\
\hline Q28 & .777 & & & & & & \\
\hline Q27 & .768 & & & & & & \\
\hline Q29 & .747 & & & & & & \\
\hline Q26 & .590 & & & & & & \\
\hline Q25 &., 423 & & & & & & \\
\hline Q18 & & .720 & & & & & \\
\hline Q16 & & .651 & & & & & \\
\hline Q19 & & .606 & & & & & \\
\hline Q17 & & .603 & & & & & \\
\hline$Q 20$ & &, 597 & & & & & \\
\hline Q15 & & .570 & .521 & & & & \\
\hline 912 & &., 442 & & & & & \\
\hline Q4 & & & .704 & & & & \\
\hline$Q 7$ & & & .663 & & & & \\
\hline Q6 & & & .589 & & & & \\
\hline Q14 & & & .516 & & & & \\
\hline Q2 & & & &, 777 & & & \\
\hline Q1 & & & & .766 & & & \\
\hline$Q 3$ & & & & .615 & & & \\
\hline Qs & & & & 591 & & & \\
\hline$Q 23$ & & & & & .774 & & \\
\hline$Q 21$ & & & & & .722 & & \\
\hline Q22. & & & & & .674 & & \\
\hline 010 & & & & & & .736 & \\
\hline 09 & & & & & & .707 & \\
\hline Q8. & & & & & .463 & .539 & \\
\hline$Q 11$ & & & & & & .482 & \\
\hline$Q 13$ & & .453 & & & & .458 & \\
\hline$Q 24$ & & & & & & & .909 \\
\hline
\end{tabular}

Nota 1: Rotation Method: Varimax with Kaiser Normalization.a

Nota 2: As variáveis Q30, Q18, Q4, Q2, Q23, Q10 são as que possuem maiores cargas fatoriais.

Nota 3: Adotou-se o critério suppress small coefficients-absolute value below 0,4 .

Fonte: Dados da pesquisa.

A Tabela 3 informa o Alfa de Cronbach, ferramenta estatística que quantifica, numa escala de 0 a 1 , a confiabilidade de um questionário, sendo o alfa é entre 0,70 e 0,90 o valor de referência (Hair et al., 2009). Optou-se por analisar a confiabilidade de cada fator, e, nesse caso, optou-se por excluir o item 24, considerando sua vinculação única a um fator e, também, leitura de que este item, conceitualmente, não se aproxima dos demais fatores. Assim, seis fatores apresentam confiabilidade de acordo com os valores alfa.

Tabela 3 - Teste de confiabilidade

\begin{tabular}{r|r|r} 
Reliability Statistics & \\
\hline $\begin{array}{r}\text { Cronbach's } \\
\text { Alpha }\end{array}$ & N. of Items & \\
\hline, 880 & 6 & Fator 1 \\
\hline, 894 & 7 & Fator 2 \\
\hline, 792 & 4 & Fator 3 \\
\hline, 778 & 4 & Fator 4 \\
\hline, 765 & 3 & Fator 5 \\
\hline, 829 & 5 & Fator 6
\end{tabular}

Nota: Com a exclusão do item 24, a escala resultante é composta por 29 itens.

Fonte: Dados da Pesquisa 
Antes de apreciar os fatores em função de seus itens, na perspectiva de designar significado (rótulo) à configuração de cada fator, inclusive considerando que as cargas mais altas devem possuir preponderância nessa significação (Hair et al. 2009), optou-se por realizar Análise Fatorial Confirmatória (AFC), a fim de obter padrão de validade e confiabilidade à escala por meio da técnica de mínimos quadrados parciais.

Para a avaliação do modelo de mensuração, recomenda-se a análise da Validade Convergente, obtida pela (Average Variance Extracted - AVEs), sob o critério de Fornell e Larcker (1981). Pela Tabela 4, observa-se que todas as variáveis latentes possuem níveis de AVE acima de recomendado (AVE > 0,50). Da mesma forma, constata-se que a Consistência interna (alpha de Cronbach) (alpha > 0,7) e a Confiabilidade Composta (Reliability composite) $(0,7<\mathrm{CC}<0,95)$, assumem valores acima da referência do primeiro caso, e dentro do esperado, no segundo (Hair Jr. et al., 2014).

Tabela 4 - Matriz de correlações entre as Variáveis Latentes

\begin{tabular}{l|r|r|r|r|r|r}
\hline & Fator1 & \multicolumn{1}{|l|}{ Fator2 } & \multicolumn{1}{l|}{ Fator3 } & Fator4 & Fator5 & Fator6 \\
\hline Fator1 & $\mathbf{0 , 8 0 2}$ & & & & & \\
\hline Fator2 & 0,729 & $\mathbf{0 , 7 8 7}$ & & & & \\
\hline Fator3 & 0,596 & 0,743 & $\mathbf{0 , 8 0 0}$ & & & \\
\hline Fator4 & 0,459 & 0,624 & 0,608 & $\mathbf{0 , 7 8 5}$ & & \\
\hline Fator5 & 0,552 & 0,551 & 0,502 & 0,393 & $\mathbf{0 , 8 3 9}$ & \\
\hline Fator6 & 0,647 & 0,743 & 0,719 & 0,567 & 0,596 & 0,780 \\
\hline Alfa & 0,889 & 0,897 & 0,812 & 0,794 & 0,789 & 0,840 \\
AVE & 0,644 & 0,619 & 0,639 & 0,616 & 0,704 & 0,609 \\
CC & 0,915 & 0,919 & 0,876 & 0,865 & 0,876 & 0,886 \\
\hline
\end{tabular}

Legenda: Alfa: Cronbach's Alpha; AVE: Average Variance Extracted; CC: Composite Reliability Nota 1: Valores em negrito na diagonal são a raiz quadrada da variância média extraída (AVE)

Fonte: Dados da Pesquisa.

Também na Tabela 4 constam as raízes quadradas das AVEs, que devem ser maiores que as correlações entre os constructos ( ${ }^{2} \sqrt{ }$ AVE > correlações de Pearson entre os construtos) (Fornell \& Larcker, 1981), indicando, portanto, que há Validade Discriminante dos constructos do modelo de mensuração. A Tabela 5, por sua vez, informa a Validade Discriminante dos indicadores. 
Tabela 5 - Validade Discriminante dos indicadores (ou itens).

\begin{tabular}{l|r|r|r|r|r|r} 
& Fator 1 & Fator 2 & Fator 3 & Fator 4 & Fator 5 & Fator 6 \\
\hline Q25 & $\mathbf{0 , 7 3 9}$ & 0,638 & 0,553 & 0,558 & 0,511 & 0,516 \\
\hline Q26 & $\mathbf{0 , 7 7 5}$ & 0,617 & 0,429 & 0,340 & 0,449 & 0,561 \\
\hline Q27 & $\mathbf{0 , 8 2 3}$ & 0,594 & 0,454 & 0,255 & 0,341 & 0,528 \\
\hline Q28 & $\mathbf{0 , 8 0 3}$ & 0,463 & 0,420 & 0,251 & 0,418 & 0,458 \\
\hline Q29 & $\mathbf{0 , 8 1 8}$ & 0,582 & 0,470 & 0,407 & 0,434 & 0,458 \\
\hline Q30 & $\mathbf{0 , 8 5 1}$ & 0,577 & 0,510 & 0,341 & 0,471 & 0,573 \\
\hline Q12 & 0,584 & $\mathbf{0 , 7 7 3}$ & 0,645 & 0,512 & 0,383 & 0,697 \\
\hline Q15 & 0,621 & $\mathbf{0 , 7 6 7}$ & 0,647 & 0,390 & 0,372 & 0,541 \\
\hline Q16 & 0,558 & $\mathbf{0 , 7 8 4}$ & 0,562 & 0,398 & 0,337 & 0,543 \\
\hline Q17 & 0,587 & $\mathbf{0 , 8 2 4}$ & 0,639 & 0,547 & 0,477 & 0,592 \\
\hline Q18 & 0,579 & $\mathbf{0 , 8 3 5}$ & 0,572 & 0,483 & 0,431 & 0,594 \\
\hline Q19 & $\mathbf{0 , 5 2 2}$ & $\mathbf{0 , 7 3 4}$ & 0,469 & 0,531 & 0,528 & 0,512 \\
\hline Q20 & 0,559 & $\mathbf{0 , 7 8 8}$ & 0,542 & 0,561 & 0,504 & 0,591 \\
\hline Q14 & 0,398 & 0,619 & $\mathbf{0 , 7 7 5}$ & 0,516 & 0,470 & 0,598 \\
\hline Q4 & 0,451 & 0,562 & $\mathbf{0 , 8 3 2}$ & 0,511 & 0,351 & 0,542 \\
\hline Q6 & 0,457 & 0,585 & $\mathbf{0 , 7 6 0}$ & 0,444 & 0,308 & 0,483 \\
\hline Q7 & 0,589 & 0,607 & $\mathbf{0 , 8 2 9}$ & 0,471 & 0,459 & 0,660 \\
\hline Q1 & 0,298 & 0,433 & 0,407 & $\mathbf{0 , 7 6 1}$ & 0,337 & 0,378 \\
\hline Q2 & 0,368 & 0,410 & 0,370 & $\mathbf{0 , 7 5 4}$ & 0,296 & 0,430 \\
\hline Q3 & 0,317 & 0,516 & 0,471 & $\mathbf{0 , 7 9 4}$ & 0,225 & 0,416 \\
\hline Q5 & 0,442 & 0,570 & 0,613 & $\mathbf{0 , 8 2 7}$ & 0,371 & 0,534 \\
\hline Q21 & 0,319 & 0,388 & 0,453 & 0,220 & $\mathbf{0 , 7 5 0}$ & 0,443 \\
\hline Q22 & 0,524 & 0,531 & 0,420 & 0,432 & $\mathbf{0 , 8 7 5}$ & 0,557 \\
\hline Q23 & 0,520 & 0,453 & 0,403 & 0,311 & $\mathbf{0 , 8 8 5}$ & 0,490 \\
\hline Q10 & 0,303 & 0,433 & 0,395 & 0,375 & 0,321 & $\mathbf{0 , 6 8 3}$ \\
\hline Q13 & 0,655 & 0,716 & 0,656 & 0,557 & 0,423 & $\mathbf{0 , 8 3 0}$ \\
\hline Q9 & 0,577 & 0,719 & 0,642 & 0,490 & 0,522 & $\mathbf{0 , 8 3 6}$ \\
\hline 0,473 & 0,506 & 0,486 & 0,391 & 0,503 & $\mathbf{0 , 7 8 3}$
\end{tabular}

Nota: As cargas dos indicadores nos constructos devem ser maiores que as cargas dos mesmos indicadores nos outros constructos

Fonte: Dados da Pesquisa.

Avaliou-se, também, as cargas fatoriais do modelo de análise (Figura 3). Todos os indicadores foram mantidos no modelo estrutural, considerando as cargas acima de 0,7. 
Figura 1 - Cargas Fatoriais do Modelo Mensuração.

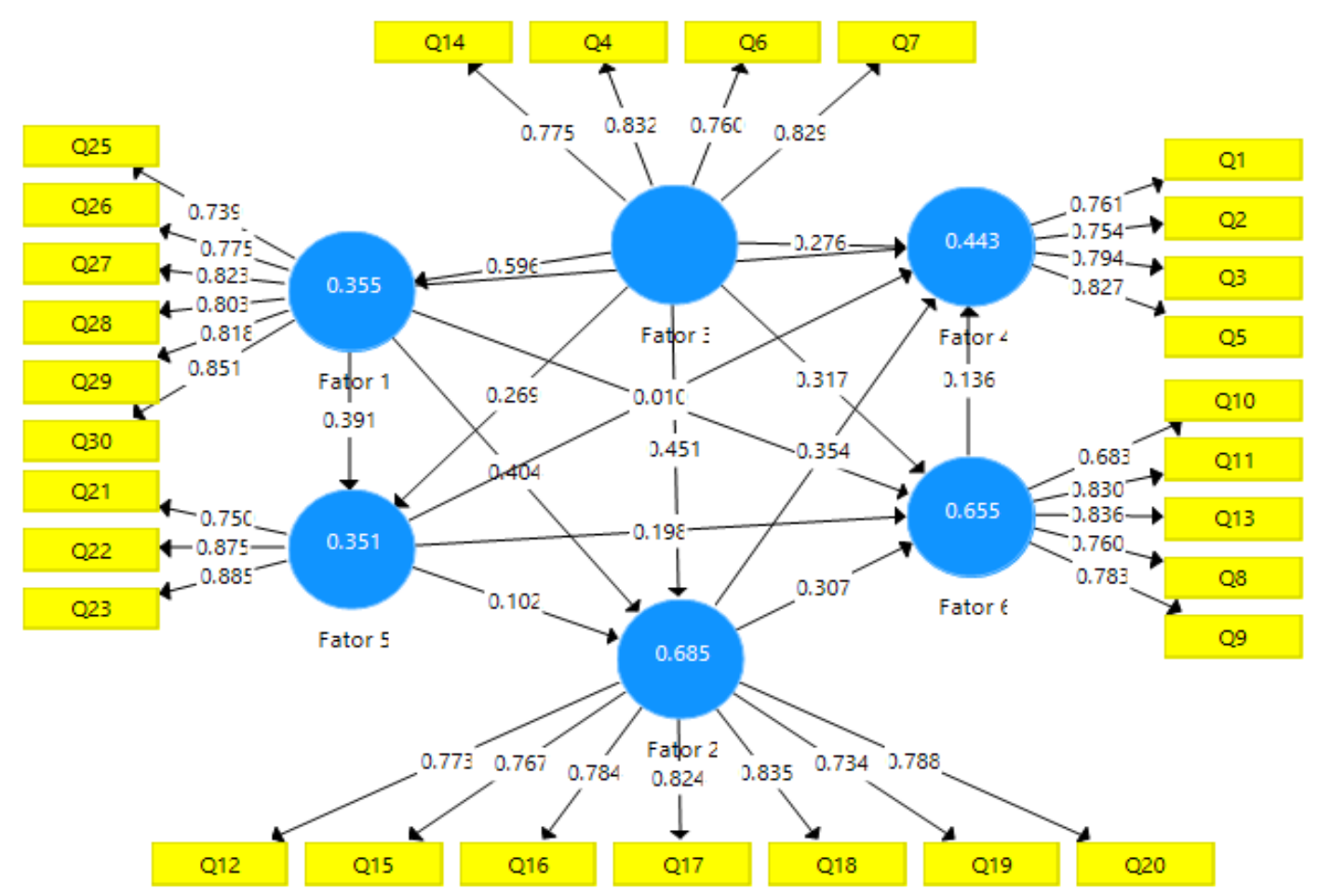

Nota: Apenas o indicador Q10 apresenta carga abaixo de 0,7 , embora, sendo o valor muito próximo $(0,68)$, optou-se por mantê-lo no modelo.

Fonte: Dados da Pesquisa.

Com o dimensionamento resultante da AFE e da AFC têm-se a possibilidade de definir cada fator. O Fator 1, concebido como "Flexibilidade" reúne itens relativos à flexibilidade, à empatia e à proatividade. Considera-se a flexibilidade como a abertura à contextos diversos e à diferentes posturas, opiniões e ações, o que reflete, também, na capacidade de empatia, no caso, na busca de compreender a posição do outro. Embora a proatividade seja inserida nesse fator, ele possui menor carga fatorial, e, com isso, uma menor relação com a dimensão. De todo modo, a flexibilidade e a empatia, definidas por Pereira (2007) como atitudes, envolve proatividade. O Fator "Flexibilidade" responde por 14,01\% da variância explicada, sendo a disposição à diferentes argumentos o item (Q30) que melhor representa o fator.

Com o Fator "Flexibilidade", confere-se a principal competência atribuída ao docente em pesquisas como as de Moura e Soares (2009), Duarte (2004) e Valente e Viana (2011), no que tange ao contexto social marcado por um mercado efêmero e que impõe a necessidade de constante formação, o que imprime a ideia de um conhecimento sempre em processo. Além disso, a empatia como uma atitude de flexibilidade à posição do outro assume especial relevo, diante da democratização do acesso ao Ensino Superior e à internacionalização, considerando a diversidade cultural que isso implica (Nassif \& Hanashiro 2005, Teichler, 2004, Guitel, 2006, Beshara, 2016, Brackmann, 2013, Souza, 2010). Nesse caso, abertura às mudanças, à novos conhecimentos, ao saber do outro (tanto do colega docente, como dos discentes), associado à proatividade situam novas demandas ao profissional docente.

O Fator 2 "Gestão de Tarefas", com 13,25\% da variância explicada, abrange itens de planejamento, liderança e visão sistêmica. A definição surge da ideia principal associada ao item (Q18) que melhor representa o fator, no caso o saber-fazer as atividades cotidianas do profissional. A “Gestão de Tarefas” define atenção ao que Pereira (2007) e Brasil (2009) ressaltam: a docência exige gestão, não apenas a gestão acadêmica (gestão de cursos, de departamentos, institutos etc.), mas a própria gestão das suas atividades inerentes. Com isso, o Fator situa a discussão de Gramigna (2004), que defende a capacidade de 
gestão na perspectiva do sucesso, haja vista a importância dessa habilidade para contornar situações complexas, em contextos mutáveis.

O Fator 3 "Domínio Didático-Pedagógico", possui a terceira maior variância explicada, no caso, 11,75\%. Integram esse Fator o domínio do conhecimento, associado à um relacionamento interpessoal saudável, à formação metodológica e à capacidade comunicativa do docente. Nesse caso, o Fator 3 envolve três componentes, conhecimento (conteúdo e metodologia), e habilidades de relacionamento e de comunicação. Com essa configuração, têm-se que o conhecimento ainda é o aspecto preponderante, representando o principal item associado ao Fator, mas agrega habilidades necessárias à construção do conhecimento pelo discente, no caso, o saber-ensinar mediado por uma relação docente-aluno propícia, o que converge com os achados de Nassif (2005) e de Marli (2010), por exemplo.

O Fator 4, "Domínio em pesquisa", confere itens no âmbito do conhecimento em pesquisa. Curiosamente, esse Fator emerge da AFE e AFC como separado do Fator 3, representando 10,26\% da variância explicada. Mesmo diante do discurso da indissociabilidade do ensino, da pesquisa e da extensão, estas, em conjunto, trazem desafios adicionais à profissão, em função do volume de demandas (Campos, Silva \& Cicillini, 2015). Têm-se, neste fator, o conhecimento para a pesquisa como específica, o que associa-se ao contexto acadêmico cada vez mais voltado à produtividade, quando a excelência do ensino é conferida com base na participação em rankings de publicação (Sguissardi \& Silva Jr, 2009).

O Fator 5, “Comportamento Ético", responde por 8,85\% da variância explicada. Estão envolvidos nesse Fator o compromisso ético diante da produção científica, item (Q23) de maior representatividade, postura ética com discentes e com os recursos públicos. De forma geral, o conteúdo ético do fator associa-se à postura de responsabilidade desse profissional diante da sua atuação, incluindo o impacto desta na sociedade, o que reflete no argumento de Masetto (2003) no que tange à importância da atitude ética/política do docente.

Por fim, o Fator 6, "Inovação e Cooperação", apresenta 4,2\% da variância explicada. Reúne habilidades no que tange à inovação (item com maior representatividade-Q10) em sintonia com a cooperação, a mediação de conflitos e abertura ao diálogo. Com isso, o Fator agrega aspectos convergentes ao que Almeida (2008) argumenta, no caso, em contextos de mudanças, em que o conhecimento é efêmero, há que se apostar na cooperação na construção de conhecimentos. Nesse caso, o compartilhar e construir coletivamente assume relevo diante de novas ideias, novas propostas de resolução de problemas.

O Quadro 1 resume a dimensionalidade das competências para o ensino e a pesquisa, sugeridas pelo presente estudo. O Tipo de competência situa como cada nova dimensão assumida se comporta em relação à conhecimentos, habilidades e atitudes definidas por Pereira (2007). 
Quadro 1 - Competências para o ensino e a pesquisa.

\begin{tabular}{|c|c|c|}
\hline Competências & Concepção & $\begin{array}{c}\text { Tipo de } \\
\text { Competência }\end{array}$ \\
\hline Flexibilidade & $\begin{array}{l}\text { Ser flexível envolve a atitude do docente diante do contexto social } \\
\text { e organização que impõe mudanças constantes. Com isso, } \\
\text { conseguir adaptar-se, apontar soluções e manter-se em processo } \\
\text { de contínua exige flexibilidade desse profissional. Ao mesmo } \\
\text { tempo, para ser flexível com outros (colegas de trabalho e } \\
\text { discentes, por exemplo) a empatia releva-se essencial, } \\
\text { principalmente quando o acesso às Instituições de Ensino } \\
\text { Superior é mais democratizado e internacionalizado. }\end{array}$ & \multirow[t]{2}{*}{ Atitudes } \\
\hline $\begin{array}{l}\text { Comportamen } \\
\text { to Ético }\end{array}$ & $\begin{array}{l}\text { O compromisso com a atuação profissional e o impacto desta na } \\
\text { sociedade manifesta-se na competência ética. Nesta o docente } \\
\text { coloca-se atento às consequências de suas ações no âmbito da } \\
\text { responsabilidade ante ao discente, à produção acadêmica e aos } \\
\text { recursos públicos. }\end{array}$ & \\
\hline $\begin{array}{l}\text { Gestão de } \\
\text { Tarefas }\end{array}$ & $\begin{array}{l}\text { Ser capaz de gerir tarefas corresponde à habilidade em planejar } \\
\text { atividades, ao mesmo tempo que se consegue liderar projetos, } \\
\text { ações coletivas, com suporte em visão sistêmica. Assim, além do } \\
\text { ensino, da pesquisa e da extensão, o docente é, cada vez mais, } \\
\text { convocado à ter habilidades de gestão, para, inclusive, equacionar } \\
\text { as múltiplas demandas de essas áreas exige desse profissional. }\end{array}$ & \multirow[t]{2}{*}{ Habilidades } \\
\hline $\begin{array}{l}\text { Inovação e } \\
\text { Cooperação }\end{array}$ & $\begin{array}{l}\text { Inovar e cooperar refletem a necessidade de transformar } \\
\text { constantemente conhecimentos na perspectiva da resolutividade. } \\
\text { Assim, o compartilhar tanto facilita o fluxo de ideias, como estas, } \\
\text { coletivamente, apontam para propostas inovadoras. }\end{array}$ & \\
\hline $\begin{array}{l}\text { Domínio } \\
\text { Didático- } \\
\text { Pedagógico }\end{array}$ & $\begin{array}{l}\text { Ter domínio de conhecimentos e habilidades interpessoais e } \\
\text { comunicacionais permitem ao docente exercer a competência } \\
\text { didático-pedagógica. Nesta, têm-se, nesse caso, o processo do } \\
\text { saber-ensinar-aprender, quando a competência se completa com } \\
\text { aprendizado do aluno. }\end{array}$ & $\begin{array}{l}\text { Conhecimento } \\
\text { /habilidades }\end{array}$ \\
\hline $\begin{array}{l}\text { Domínio em } \\
\text { Pesquisa }\end{array}$ & $\begin{array}{l}\text { Ter conhecimento para a pesquisa é competência do docente } \\
\text { associada à demanda por produçãa acadêmica, intensificada nos } \\
\text { últimos anos em função da relação rankings-excelência-recursos- } \\
\text { sucesso }\end{array}$ & Conhecimento \\
\hline
\end{tabular}

Fonte: Autores.

\section{Discussão}

Com a Análise de Conteúdo das entrevistas foi possível identificar alguns segmentos de texto referentes a cada competência dimensionada na pesquisa. Como as questões foram levantadas na perspectiva da sustentabilidade profissional, as concorrências exemplificaram relações entre as competências e as demandas atuais para o docente. O Quadro 2 ilustra os trechos selecionados. 
Quadro 2 - Trechos selecionados das entrevistas.

\begin{tabular}{|c|c|}
\hline Flexibilidade & Domínio em Pesquisa \\
\hline $\begin{array}{l}\text { Para que você possa garantir a } \\
\text { sustentabilidade da sua profissão, você tem } \\
\text { que estar em consonância com as } \\
\text { necessidades da sociedade (E1) } \\
\text { (...) no sentido da sustentabilidade (...) uma } \\
\text { certa readaptação, reorganização e } \\
\text { reinvenção aos desafios que o contexto lhe } \\
\text { impõe. (E2) } \\
\text { profissional docente sustentável seria } \\
\text { aquele que seria capaz de atender as } \\
\text { exigências desse contexto educacional atual } \\
\text { (E2) } \\
\text { (...) a aproximação dessa função docente com } \\
\text { essas necessidades do mercado tem } \\
\text { mesclado o papel docente com o papel } \\
\text { profissional (E2) } \\
\text { (...) poder reflexivo, visão complexa, } \\
\text { diálogos, escuta atenta (E2) }\end{array}$ & $\begin{array}{l}\text { (...) a pesquisa deve ser o centro, o eixo principal (...) } \\
\text { é na pesquisa que o professor cria novas formas de } \\
\text { ensino, de metodologias (...) na pesquisa você } \\
\text { vivencia aquele conhecimento. Então na hora que } \\
\text { você vivencia, você internaliza muito mais (E1) } \\
\text { Existe a profissão pesquisador e a profissão instrutor } \\
\text { (...). Nem todo professor das universidades ensinam } \\
\text { e obviamente, nem todos os professores e na grande } \\
\text { maioria não atuam na pesquisa. (E2) } \\
\text { O MEC está mais voltado para (...) a pós graduação } \\
\text { e particularmente no estrito senso (...) A usina de } \\
\text { produção acadêmica se encontra inserida na pós } \\
\text { graduação e stricto senso (E2) } \\
\text { A postura do professor pesquisador está quando eu } \\
\text { pego um assunto e digo assim: Analise esse artigo } \\
\text { aqui. O que esse artigo pode está errado? Não } \\
\text { professor esse é um artigo seu. Mas vamos criar } \\
\text { uma análise crítica, vamos atrás da literatura, o que } \\
\text { contradiz a esse artigo? O que que nega esse artigo? } \\
\text { Isso é ciência, você a parti daí criar um novo } \\
\text { conhecimento (E2) }\end{array}$ \\
\hline & \\
\hline $\begin{array}{l}\text { (...) com um mínimo dano possivel ao meio } \\
\text { ambiente e no ambiente corporativo, } \\
\text { institucional ou acadêmico, por exemplo, } \\
\text { usando os recursos da forma mais eficiente, } \\
\text { da forma mais adequada, com o menor dano } \\
\text { possível, inclusive a ecologia institucional } \\
\text { (E2) } \\
\text { (...) O professor que eu vou lembrar é } \\
\text { aquele que trouxe outros referenciais, } \\
\text { trouxe atividades de extensão e de } \\
\text { responsabilidade social, discutiu política, } \\
\text { discutiu cultura, levou o aluno para outros } \\
\text { espaços e essa é uma competência muito } \\
\text { dificil de alcançar (E2) }\end{array}$ & $\begin{array}{l}\text { (...) aula, aula, aula, aula, ele é enxotado, por que o } \\
\text { aluno não quer mais isso, ele não espera só isso (E2) } \\
\text { O aluno quer contribuir, ele quer participar, quer } \\
\text { interagir e é isso que se o professor não cria } \\
\text { mecanismo, método, não muda a abordagem para } \\
\text { criar esse espaço (...) (E2) } \\
\text { (...) o que é muito exigido na prática docente é a } \\
\text { vivência no mercado, hoje não se quer mais o } \\
\text { professor doutor de aula (...), mas será que não é } \\
\text { um pouco impossível, ele ser o docente e ao mesmo } \\
\text { tempo está no mercado e conciliar? (E3) }\end{array}$ \\
\hline & \\
\hline $\begin{array}{l}\text { Eu tenho que resolver as questões } \\
\text { educacionais da melhor forma possivel (E2) } \\
\text { (..) a docência hoje, você trabalha a docência } \\
\text { em um escopo muito grande de ações (E2) } \\
\text { (...) gestão, eu sou um gestor, por que o meu } \\
\text { desenvolvimento docente não incorpora } \\
\text { programas de desenvolvimento gerencial? } \\
\text { como gestor, é uma função docente, eu sou }\end{array}$ & $\begin{array}{l}\text { (...) inovação é extremamente importante, para que } \\
\text { você crie coisas novas, não seja simplesmente um } \\
\text { replicador do conhecimento, e sim, você gere novos } \\
\text { conhecimentos. Então, acho que, para você atender } \\
\text { às necessidades, porque o próprio termo diz, } \\
\text { inovação é o quê? É você atender a uma necessidade } \\
\text { que até então não estava sendo atendida (E1) } \\
\text { (...) O docente do século XXI não é o cara que sabe } \\
\text { muito, (...) ele não faz isso sozinho (E2). }\end{array}$ \\
\hline
\end{tabular}

Fonte: Dados da pesquisa.

Pelo Quadro 2 identifica-se que a sustentabilidade da profissão se associa às demandas da sociedade, particularmente do mercado de trabalho. Esta visão é a que sustenta essa pesquisa, situada nos argumentos de Moura e Soares (2009), Duarte 
(2004) e Almeida (2008), por exemplo. A flexibilidade envolve a adaptação do docente às demandas mercadológicas, quando a capacidade reflexiva, o coloca ativo da reinvenção de suas atividades.

O comportamento ético surge associado ao compromisso com o meio ambiente e com a instituição, sendo o conteúdo político projetado como uma competência rara, embora sendo intensamente valorizada. No que tange à gestão de tarefas, as citações envolvem o aporte de ações que esse profissional vem assumindo com o tempo e mesmo a gestão acadêmica de cursos, departamentos etc. A gestão é lembrada como componente essencial, embora a formação para essa função ainda seja negligenciada na concepção dessa profissão, o que aponta importante desafio à sustentabilidade dessa competência.

A Inovação e a Cooperação são requisitadas à formação de novos conhecimentos em função de necessidades emergentes, ao passo que nessa construção o docente é convocado a construir coletivamente. No âmbito do domínio didáticopedagógico, têm-se que o ato de "ensinar" não mais atende às necessidades dos discentes, ao passo que estes buscam, cada vez mais, interagir, o que exige a mobilização de outras competências, no caso, a própria capacidade de interação e comunicação do docente.

No que diz respeito à pesquisa, há ênfase no fato dela "dever ser" o centro da atuação docente. No entanto, têm-se, ainda, distância entre o ensino e a pesquisa, ao passo que se constitui dois tipos de profissionais, o docente instrutor e o docente pesquisador. Nesta concepção, aquele que se envolve com a pesquisa acaba recebendo importante incentivo em função de políticas voltadas para a produção científica e distancia-se das atividades de ensino na graduação. Mesmo que essa seja definida como uma realidade, das falas deriva-se que a sustentabilidade da profissão está associada a equilibrar atuação no ensino e na pesquisa. A primeira, coordenada com a experiência da prática profissional no mercado, a segunda em função da produtividade em pesquisa. No entanto, coloca-se em questão até que ponto uma mesma pessoa consegue equilibrar essas funções.

\section{Conclusão}

A universidade encontra-se em processo de transformação, ela não é mais um celeiro de informação, ela é um espaço para reflexão sobre o conhecimento. E quais as competências sustentáveis para atender as demandas da contemporaneidade do docente universitário foi o principal questionamento do estudo.

A pesquisa centra esforços na busca de dimensionar competências docentes e compreendê-las à luz das demandas profissionais da atualidade. Nesse sentido, de 13 competências para o ensino e a pesquisa definidos por Pereira (2007), a pesquisa quantitativa fez emergir seis dimensões (Flexibilidade, Comportamento ético, Gestão de tarefas, Inovação e Cooperação, Domínio Didático-Pedagógico e Domínio em Pesquisa).

No âmbito do agrupamento das dimensões, têm-se que competências sustentáveis se alinham à flexibilidade, que se desdobra em empatia e proatividade. Estas, em conjunto, informam a necessidade de adaptação do profissional ante o mercado que se apresenta efêmero; a capacidade multifuncional, agregando habilidade com a gestão, no sentido de saber-fazer diante de múltiplas atividades cotidianas, inclusive gestão da carreira, incluindo atuações no âmbito do ensino, da pesquisa e da extensão; o potencial didático-pedagógico desse profissional alia conhecimentos em sintonia com um ambiente interativo com os discentes, ao passo que a comunicação sustenta essa competência.

É tido como sustentável, ainda, o compromisso ético diante da responsabilidade social e política da atuação desse profissional, inclusive por ser este formador de opinião; a Inovação e a Cooperação, diante da premissa de um conhecimento que se apresenta cada vez mais fugaz e, por isso, em construção coletiva permanentemente na busca de formulações inovativas.

A competência para a pesquisa surge como fator-chave nesse estudo, haja vista sua indicação como competência específica no âmbito quantitativo, o que reflete a realidade discutida pelas entrevistas, mas, ao mesmo tempo, sua integração com o ensino é requisitada na busca de superação de problemas, haja vista que por meio da pesquisa se torna possível gerar 
conhecimento mais reflexivo e contextualizado.

Duas ponderações. A pesquisa não assume crítica ao mercado, no sentido de questionar se a competência sustentável deve existir. Aponta-se que, teoricamente e empiricamente, há confluências no âmbito de associar competências sustentáveis do docente à empregabilidade, às demandas do mercado e, com isso, sua adaptação a este. Todavia, a pesquisa é empreendida em Instituição de Ensino Superior privada, cujo sentido "mercado educacional” ganha maior relevo. Essa questão gera importante indicação para estudos futuros, haja vista que, assim como emerge alguns questionamentos sobre mercado nos relatos, em instituições públicas o aspecto pode suscitar reflexões mais profundas.

A outra ponderação diz respeito ao volume de respondentes vinculados exclusivamente ao ensino de graduação (60\%) e o percentual de $25 \%$ de doutores. Esses dados podem, de fato, repercutir na separação do ensino e da pesquisa, haja vista que a formação em nível de doutorado oferece maiores oportunidades de atuação em pesquisa. Com isso, análises comparativas por nível de ensino e por titulação pode agregar novas configurações no âmbito das competências.

Por fim, têm-se a limitação da pesquisa no sentido não avançar na análise da extensão, inclusive pela opção do instrumento quantitativo adotado. Nesse caso, mesmo que a extensão tenha sido levantada em entrevista, embora com pequeno retorno, não foi possível compreender a extensão na perspectiva das competências. Nesse caso, ampliar o instrumento para atender quesitos no âmbito da extensão favorece avanço do que tange a compreender as competências do docente para o ensino, a pesquisa e a extensão.

\section{Referências}

Addor, F (Org.) (2015). Extensão e Políticas Públicas - o agir integrado para o desenvolvimento social. Editora UFRJ.

Addor, F. \& Henriques, F. C. (Org.) (2015) Tecnologia, participação e território - reflexões a partir da prática extensionista. Editora UFRJ.

Addor, F. \& Lianza, S. (Org.) (2015) Percursos na extensão universitária - saindo da torre de marfim. Editora UFRJ.

Almeida, F. (2008). Os desafios da sustentabilidade: uma ruptura urgente. Campus Elsevier.

Arocena, R. \& Sutz, J. (2005). Latin American Universities: from an original revolution to an uncertain transition. Higher Education, 50, 573-592.

Bardin, L. (2011). Análise de Conteúdo. Edições 70.

Barney, J. B. \& Hesterly, W. S. (2007). Administração Estratégica e Vantagem Competitiva: casos brasileiros. Pearson.

Beshara, G. (2016). Educação e política externa: a experiência brasileira no Mercosul Educacional. http://www.users.rdc.puc-rio.br/agendas_de_politica_externa_iri /pdfs /ec/rel_ic_/rel-ac-gregory.pdf.

Bezerra, F. A. (2012). Análise Fatorial. In: Corrar, L. J, et al. (Org.). Análise Multivariada: para os Cursos de Administração, Ciências Contábeis e Economia. 1 ed, 4. Reimpr, São Paulo: Atlas.

Bonfim, R. M. (2012). Competência profissional: uma revisão bibliográfica. Revista Organização Sistêmica, 1 (1).

Boog, G. G. (1991). O desafio da competência: Como enfrentar as dificuldades do presente e preparar sua empresa para o future. Best Seller.

Brackmann, M. M. (2013) A Internacionalização da Educação Superior e Política externa brasileira: A contribuição da UNILA. Competências, Porto Alegre, RS, 6 (1), 11-29.

Brasil. Decreto-lei n 205 (2009). Diário da República, $1^{\text {o }}$ série, $\mathrm{n}^{\mathrm{o}}$ 168, 31 de agosto de 2009. (Revisão dos estatutos das carreiras docente do ensino universitário, de investigação, e docente do ensino superior politécnico).

Campos, V. T. B., Silva, F. A. \& Cicillini, G. A. (2015) Os sentidos dos silêncios na educação: representações sociais de professores formadores da Universidade Federal de Uberlândia. MG. ETD: Educação Temática Digital, 17, 442-462.

Duarte, M. E. (2004). O indivíduo e a organização: Perspectivas de desenvolvimento. Psychologica, Special issue, $549-557$.

Dudziak, E. A. (2003). Análise das competências essenciais nos grupos de pesquisa: estudo do caso em três laboratórios na escola politécnica da USP. In: Simpósio de Gestão da Inovação Tecnológica, 23, 2003, Anais... São Paulo, 2863-2877.

Dutra, J. S. (2004). Competências conceitos e instrumentos para a gestão de pessoas na empresa moderna. Atlas.

Ferreira, L. R. (2015). O trabalho do Professor Jovem-Doutor na Pós-Graduação: produção de conhecimento e discurso do professor, Tese de Doutorado em Educação, Universidade Federal de São Carlos. 
Fleury, M. T. L. \& Fleury, A. (2001). Construindo o Conceito de Competência. Revista de Administração Contemporânea, $183-196$.

Fleury, M. T. L \& Fleury, A. (2004). Estratégias empresariais e formação de competências: um quebra-cabeça caleidoscópio da indústria brasileira. (3a ed.), Atlas.

Fornell, C. \& Larcker, D. F. (1981). Evaluating structural equation models with unobservable variables and measurement error. Journal of Marketing Research. 18 (1), 39-50.

Freire, P. (1997). Pedagogia da autonomia: saberes necessários à prática educativa. Paz na Terra.

Guitel, V. (2006). Intercultural or Cross Cultural Management? The confirmation of the research field and the issue concerning the definition and the development of an intercultural competency for expatriates and international managers. Revista Economia e Gestão (E\&G), 6 (12).

Hamel, G. \& Prahalad, C. K. (1995). Competindo pelo futuro: estratégias inovadoras para obter o controle do seu setor e criar os mercados de amanhã. Campus.

Healey, M. (2005). Linking research and teaching: exploring disciplinary spaces and the role of inquiry-based learning. In: Barnett, R (Ed.). Reshaping the University: New Relationships between Research, Scholarship and Teaching. McGraw Hill: Open University Press.

Joly, M. C. R., Silva, B. D. \& Almeida, L. S. (2012). Avaliações das competências docentes para utilização das tecnologias digitais. Currículo sem Fronteiras, 12 (3), 83-96, set./ dez.

Hair, Jr. et al. (2009). Análise Multivariada de Dados. Tradução Adonai Schlup Sant Ánna e Alselmo Chaves Neto. (6a ed.) Bookman.

Hair Jr., J., Gabriel, M. \& Patel, V. (2014). Modelagem de Equações Estruturais baseada em Covariância (CB-SEM) com o AMOS: orientações sobre a sua aplicação como uma ferramenta de pesquisa de Marketing. Revista Brasileira de Marketing, 13 (2), 43-53.

Hair, J. F., Hult, T. M., Ringle, C. M. \& Sarstedt, M. (2014). A Primer on Partial Least Squares Structural Equation Modeling (PLS-SEM). Los Angeles: SAGE.

Knowles, M. (1980). The modern practice of adult education, revised and updated. Englewood Cliffs: Prentice Hall Regents.

Le Boterf, G. (2003). Desenvolvendo a competência dos profissionais. Artmed.

Leite Filho, G. A. R. \& Martins, G. A. (2006). Relação orientador orientado e suas influências no processo de elaboração de e dissertações. Revista de Administração Eletrônica-RAE, Ed. especial.

Lima, G. C. (2003). O Discurso da sustentabilidade e suas implicações para a educação. Ambiente \& Sociedade, 6 (2), $99-119$.

Marli, A. (2010). Formação de professor: A constituição de um campo de estudos. Educação. 33 (3), 174-181.

Masetto, M. T. (2003). Competência pedagógica do professor universitário. Summus.

Malhotra, N. K. (2012). Pesquisa de marketing: uma orientação aplicada. (6a ed.), Bookman.

Marôco, J. (2014). Análise de equações estruturais: fundamentos teóricos, software \& aplicações. (2a ed.), Pêro Pinheiro: ReportNumber.

McClelland, D. C. (1973). Testing for competence rather than for "intelligence". American Psychologist, 1-14.

Medeiros, A. C. P. (2007). Análise da relevância das competências individuais para o ensino: Um estudo de caso no curso de Administração da Faculdade de Ciências humanas e Sociais da Igarassu - PE. Dissertação (Mestrado em Administração) - Centro de Pesquisa em Administração, Faculdade de Boa Viagem, Cidade.

Michaux, V. (2011). Articular as competências individual, coletiva, organizacional e estratégica: esclarecendo a teoria dos recursos e do capital social. In.: Retour, D. et al. Competências coletivas: no limiar da estratégia. Bookman.

Minayo, M. C. S. (2014). O desafio do conhecimento: pesquisa qualitativa em saúde. (14a ed.), Hucitec.

Moura, M. A. M. \& Soares, F. (2009). A Sustentabilidade da Carreira dos Profissionais no Século XXI: Reflexões sobre as Competências Baseadas no Comportamento de Entrega e o Mito Proteu. Revista Gestão \& Tecnologia, Pedro Leopoldo, 9 (2), 1-16.

Nassif, V. M. J. \& Hanashiro, D. M. M. (2005). Competências de Professores: Um Fator Competitivo. Revista Brasileira de Gestão de Negócios-RBGN, São Paulo, 8 (20), 45-56.

Nassif, V. M. J., Hanashiro, D. M. M. \& Torres, R. R. (2010). Fatores que influenciam na percepção das competências para o exercício da docência. Revista Brasileira de Educação, 15, (44), 364-379.

Nivala, M. (2009) Simple answers for complex problems: education and ICT in Finnish information society strategies. Media, Culture \& Society, SAGE Publications, Los Angeles, London, New Delhi and Singapore, 31 (3), 433-448.

Pereira, M. A. C. (2007). Competências para o ensino e a pesquisa: Um Survey com docentes de engenharia química. Tese (Doutorado em Engenharia de Produção) - Escola Politécnica, Universidade de São Paulo, São Paulo.

Perrenoud, P. (2000). Dez novas competências para ensinar. Artes Médicas Sul.

Prahalad, C. K. \& Hamel, G. (1990). The core competence of the corporation. Harvard Business Review, Boston, 68 (3), $79-91$. 
Research, Society and Development, v. 10, n. 1, e47810112007, 2021

(CC BY 4.0) | ISSN 2525-3409 | DOI: http://dx.doi.org/10.33448/rsd-v10i1.12007

Rebelo, P. V., Pessoa, T. \& Barreira, C. (2010). Ser Professor Universitário: estudo exploratório em torno de concepções e de práticas. Revista Portuguesa de Pedagogia, 44 (1), 63-82.

Ruas, R. (2005). Gestão por competências: uma contribuição à estratégia das organizações. In: Ruas, R. L., Antonello, C. S. \& Boff, L. H. (Org.). Aprendizagem organizacional e competências. Porto Alegre: Bookman.

Severino A. J. (2013). Da docência no ensino superior: condições e exigências, Comunicações, Piracicaba, 20 (1) 43-52.

Sguissardi, V. \& Silva Júnior, J. R. (2009) Trabalho intensificado nas federais: Pós-graduação e produtivismo acadêmico. Xamã Editora.

Souza, J. J. M. (2010). A internacionalização e a mobilidade na educação Superior: O debate na America latina. 10 (2)

Teichler, U. (2004). The Changing debate on Internationalization of higher education. Higher Education, 48, 5-46.

Ubeda, C. L. (2003). A gestão de competências em uma empresa de pesquisa e desenvolvimento. Dissertação (Mestrado em Engenharia de Produção) - Escola de Engenharia de São Carlos, Universidade de São Paulo, São Carlos.

Vasconcelos, F. C. \& Cyrino, A. B. (2000). Vantagem competitiva: os modelos teóricos atuais e a convergência entre estratégia e teoria organizacional. Revista de Administração de Empresas, 40 (4), 20-37.

Veiga, I. P. A. (2011). A docência na Educação Superior e as didáticas especiais: campos em construção, Educação, Santa Maria, 36 (3), $455-464$.

Zarifian, P. (2001). Objetivo competência: por uma nova lógica. Atlas, 2001. 